\title{
Legs and Claws Condition and Lameness in Sows
}

\author{
Renata RELIĆ ${ }^{*}$, Dragan ROGOŽARSKI ${ }^{2}$, Radomir SAVIĆ ${ }^{1}$, Mila SAVIĆ ${ }^{3}$, Jovan BOJKOVSKI ${ }^{3}$ and Zsolt \\ BECSKEI $^{3}$ \\ ${ }^{1}$ University of Belgrade, Faculty of agriculture, Serbia \\ ${ }^{2}$ Specialistic Veterinary Institute "Pozarevac", Požarevac, Serbia \\ ${ }^{3}$ University of Belgrade, Faculty of veterinary medicine, Serbia \\ *corresponding author: rrelic@agrif.bg.ac.rs \\ Bulletin UASVM Veterinary Medicine 73(2) / 2016, \\ Print ISSN 1843-5270; Electronic ISSN 1843-5378 \\ DOI:10.15835/buasvmcn-vm: 12106
}

\begin{abstract}
Lameness is a multi-factorial condition that depends on managerial as well as genetic variables, but often is related to legs and feet condition of the animals. The aim of the study was to give an overview of the condition of legs and claws, and the presence of lameness in sows in one industrial farm. A total number of 130 animals (90 dry i.e. pregnant and 40 lactating sows) were observed. The occurrence of joints swellings, claw problems (long toes, dew claw problems, cracked hoof walls) and lameness (in animals in collective boxes) were visually recorded and then classified according to the appropriate protocols. The results showed the occurrence of one or more of the assessed conditions in $40 \%$ of pregnant sows and in $45 \%$ of sows in lactation. More than $20 \%$ of the pregnant sows were lame. A statistically significant positive correlation was found between the prevalence of lameness and leg swellings and between lameness and claw problems in pregnant sows (in both cases $\mathrm{p}<0.0001$ ). The results proved that lameness is a significant problem in the studied farm. In general, more attention should be given to the monitoring of sows' physical condition and behaviour, to minimize the occurrence of welfare problems and to reduce production losses.
\end{abstract}

Keywords: claw lesions, lameness, leg swellings, sows, welfare

\section{INTRODUCTION}

Problems in locomotion are very common in pigs kept in industrial farming conditions. Lameness is a multi-factorial condition that depends on managerial as well as genetic variables, but often is related to legs and feet condition of the animals (Pluym et al., 2011; Nalon et al., 2013). It is proven that specific types of claw lesions are associated with an increased risk of lameness (Anil et al., 2007). Furthermore, lameness is often a reason for lower reproductive performances and premature culling of sows (Anil et al., 2005; Pluym et al., 2012; Lisgara et al., 2015).

Claw lesions and lameness have a negative impact on welfare and production, causing important losses to the pig sector. The possibility to recognise, treat and prevent these disorders depends on the availability of reliable and valid assessment methods, as it is described in paper by Nalon et al. (2013).

Data on the extent of the leg and claw problems in the Serbian pig farms are not easily available. In farm records these problems are registered as one of the reasons for sows' culling. However, continuous monitoring for lameness is not a common praxis and the number of the animals at risk is not exactly known. The aim of the study was to give an overview of leg and claws problems and the presence of lameness in sows in a commercial farm.

\section{MATERIALS AND METHODS}

This study was carried out in a high capacity commercial pig farm in Serbia with a total number of 1285 sows. During the gestation period the sows were group-housed in boxes with, solid, 
slatted and combined floors without bedding (4 to 5 animals in $7.5 \mathrm{~m}^{2}$ box). During lactation they were in standard farrowing crates with semislated floors $\left(1.43 \mathrm{~m}^{2}\right.$ for the sow, $6.07 \mathrm{~m}^{2}$ for her piglets; total box surface $7.5 \mathrm{~m}^{2}$ ).

About $10 \%$ of total number i.e. 130 animals (90 pregnant i.e. dry and 40 sows in lactation) were assessed in their boxes for leg swellings and claw lesions, and the dry sows also for lameness. The boxes have been randomly selected (every third box in the row) as well the sows in collective boxes ( 3 animals in each collective box). All three parameters were assessed visually, using a scale from 0 to 2 from appropriate protocols: for leg swellings the AssureWel swine protocol (AssureWel, 2015), for claw lesions identification (toes length, dew claw condition and cracked wall) modification of ZinPro method (Feet First Team, 2010), and for sows locomotion assessment the Welfare Quality assessment protocol for pigs (Welfare Quality ${ }^{\circledR}, 2009$ ), respectively were used. Data on the reasons for culling and number of sows culled in the previous year were taken from the farm records.

The obtained data were processed using Kruskal-Wallis test, by SAS® 9.3 Software and Microsoft Office EXCEL 2010.

\section{RESULTS AND DISCUSSION}

Table 1 shows the data regarding the prevalence of leg swellings in dry and lactating sows.

According to table 1, the results were similar for both categories, no significant difference was found and showed that differences are not significant $(p>0.05)$. Most of the animals were without any leg swellings (96.67\% dry and 95\% lactating sows), what is better result than in a study of Knage-Rasmussen (2014). In some animals small sized swellings were noticed (in $3.33 \%$ of the dry and $5 \%$ of the lactating sows), and there were no animals with large swellings on their legs.

Much higher number of animals with leg tumefactions can be expected to be found in farrowing houses, considering that these spend most of their time lying on a hard surface. Leg swellings are caused by inadequate environment and are associated with poor flooring conditions and lack of bedding material. Most often, they are manifested as bursitis, a specific condition, which arises from constant pressure and trauma to the skin overlying any bony prominence. Bursae are most prevalent in the hock region of the hind limbs. Leg swellings may be associated with abnormal posture, locomotion and foot lesions of the hind limb and therefore especially if painful, have a detrimental effect on pig welfare (Gillman et al., 2009; WelfareQuality®, 2009; AssureWel, 2015).

Examination of claws condition gave similar results, namely the differences between the two categories of sows were not significant ( $p>0.05)$ :

Dew claws: 0 - slightly longer than normal; 1 - claws extend to floor surface when the pig is standing; 2 - claw is torn and/or partially or completely missing.

Cracked wall horizontal: 0 - haemorrhage evident, short/shallow horizontal crack in toe wall; 1 long but shallow horizontal crack in toe wall; 2 Multiple or deep horizontal crack(s) in toe wall. Cracked wall vertical: 0 - short/shallow vertical crack in toe wall; 1 - long but shallow vertical crack in toe wall; 2 - multiple or deep vertical $\operatorname{crack}(\mathrm{s})$ in toe wall.

Claw lesions are of various types and prevalence. Of particular importance, due to their high prevalence and association with lameness, Anill et al. (2008) stand out cracks of the outer wall and white line lesions. In our study, in most of the animals (57.63\% dry and $57.50 \%$ lactating sows), mild changes were noticed, usually slightly longer dew claw. However, in $36.66 \%$ dry and $42.50 \%$

Tab. 1. The prevalence of leg swellings in dry and lactating sows

\begin{tabular}{|c|c|c|}
\hline \multirow{2}{*}{ Score* } & \multicolumn{2}{|c|}{ Sows (\%) } \\
\hline & Dry & Lactating \\
\hline 0 & 96.67 & 95.00 \\
\hline 1 & 3.33 & 5.00 \\
\hline 2 & 0 & \\
\hline
\end{tabular}


lactating sows more serious problems have been noticed, scored as 1 and 2. Cracks are visible if the wall of claw is sufficiently clean, so it is possible that some cases were missed.

According to other authors (Anill at al., 2007; Pluym et al., 2011, 2013) prevalence of claw lesions in the breeding herd could be up to 80 $90 \%$. However, our results could be influenced by the fact that we did not take into account lesions at the heels' level. Changes in that region are visible only if the animal is not in standing position; the point of this study was to check animals causing minimal disturbance, without forcing them to lay down.

Claw lesions in pigs may cause lameness immediately due to the pain associated with the lesion or may act as an entry point for infections that spread upwards, affecting the internal structures of the foot. Group housing makes high demands on the locomotor system, particularly the feet of sows. It has been reported that about $80 \%$ of lameness in these systems is associated with foot problems (Anill et al., 2008).
Table 3 shows the prevalence of lameness in dry sows kept in groups, in collective boxes.

The most of the sows (76.67\%) have had no problems in locomotion or they were barely noticeable. In $23.33 \%$ of dry sows severe problems in locomotion were presented (score 1 and 2). In a couple of papers of Pluym et al. $(2011,2013)$ data on the average prevalence of lameness about $10 \%$ or below this value are provided, but it can reach up to $28 \%$.

Strength and significance of correlation between observed parameters is shown in Table 4 .

In a research of Pluym et al. (2011) locomotor disorders are the second reason for the (early) culling of sows. According to the records, in previous year $10.70 \%$ sows from the examined farm were culled because of lameness or immobility related to problems in legs or claws. Results from this study shows that $40 \%$ of the dry and $45 \%$ of the lactating sows have had changes in one or more of the examined parameters. In dry sows, $12.22 \%$ have had problems with claws

Tab. 2. Occurrence of claw lesions in dry and lactating sows

\begin{tabular}{ccc}
\hline \multirow{2}{*}{ Score* } & \multicolumn{3}{c}{ Sows (\%) } \\
\cline { 2 - 3 } & Dry & Lactating \\
\hline 0 & 57.63 & 57.50 \\
1 & 34.44 & 37.50 \\
2 & 2.22 & 5.00 \\
\hline Toes length: 0 - one or more toes slightly longer than normal; 1 - one or more toes significantly longer than normal; 2 - long toes that \\
affect gait when walking.
\end{tabular}

Tab. 3. The prevalence of lameness in dry sows

\begin{tabular}{cc}
\hline Score* & Dry sows (\%) \\
\hline 0 & 76.67 \\
1 & 20.00 \\
2 & 3.33 \\
\hline \% - normal gait, or the animal has difficulties walking but is still using all its legs; 1 - severe lame (asymmetric walking); 2 - no weight- \\
bearing on the affected limb, or the animal is unable to walk.
\end{tabular}

Tab. 4. Correlation between different parameters assessed in dry and lactating sows

\begin{tabular}{ccccc}
\hline Sows & Parameters & $\mathrm{N}$ & $\mathrm{r}_{\mathrm{s}}$ & $\mathrm{p}$-value \\
\hline \multirow{3}{*}{ Dry } & Leg swellings \& Lameness & 90 & 0.4038 & $<0.0001$ \\
\cline { 2 - 6 } & Leg swellings \& Claw problems & 90 & 0.1092 & 0.3054 \\
\cline { 2 - 6 } & Claw problems \& Lameness & 90 & 0.4381 & $<0.0001$ \\
\hline Lactating & Leg swellings \& Claw problems & 40 & 0.0228 & 0.8888 \\
\hline - -number of sows; $\mathrm{r}_{\mathrm{s}}$-Spearman correlation coefficient & & &
\end{tabular}


and lameness and $2.22 \%$ had all three problems simultaneously.

The relation between leg and claw problems and appearance of lameness is well known (Anill et al., 2007). In our study significant positive correlations were found ( $p<0.0001$, both) between leg swellings and lameness, leg swellings and claw problems and lameness (Table 4).

\section{CONCLUSIONS}

This study showed that in both categories of the assessed sows almost half of the animals have had some problems in their legs, claws or both. The appearance of leg swellings was not frequent in the investigated farm. Claw lesions were more noticeable, and more than third of animals in both categories, dry and lactating sows, have had some lesions of their claws. The prevalence of lame animals was not low but it was in accordance with the findings of other authors, as well as the significant positive correlation between leg swellings and claw problems with lameness, found in dry sows.

This research gave the overview of the current situation at the farm, taking into account the selected sample of animals. As such, they represent a good basis for further research on this and other pig farms, and for creating strategies to minimize the problems.

\section{ACKNOWLEDGEMENTS}

This paper is supported by the projects of the Ministry of Education, Science and Technological Development of Republic of Serbia, TR 31085.

\section{REFERENCES}

1. Anil SS, Anil L, Deen J (2005). Evaluation of patterns of removal and associations among culling because of lameness and sow productivity traits in swine breeding herds. Journal of the American Veterinary Medical Association 226: 956-961.

2. Anil SS, Anil L, Deen J, Baidoo SK, Walker RD (2007). Factors associated with claw lesions in gestating sows. J Swine Health Prod 15:78-83.

3. Anil SS, Deen J, Schuttert M (2008). Claw lesions and sow housing systems. International Pig Topics23 (1):7-8.

4. AssureWel (2015). Sow illustrated protocol. http://www. assurewel.org/pigs

5. Feet First Team (2010). Feet First swine claw lesion identification. Retrieved June 8, 2016, from: http://www. zinpro.com/lameness/swine/lesion-identification.

6. Gillman CE, KilBride AL, Ossent P, Green LE (2009). Preventive Veterinary Medicine 91(2-4):146-52.

7. Knage-Rasmussen KM, Houe H, Rousing T, Sørensen JT (2014). Animal 8 (1):121-127.

8. Lisgara M, Skampardonis V, Angelidou E, Kouroupides S, Leontides L (2015). Associations between claw lesions and reproductive performance of sows in three Greek herds. Veterinarni Medicina 60 (8): 415-422.

9. Nalon E, Conte S, Maes D, Tuyttens FAM, Devillers N (2013). Assessment of lameness and claw lesions in sows. Livestock Science 156:10-23.

10. Pluym L, Van Nuffel A, Dewulf J, Cools A, Vangroenweghe F, Van Hoorebeke S, Maes D (2011). Prevalence and risk factors of claw lesions and lameness in pregnant sows in two types of group housing. Veterinarni Medicina 56 (3):101-109.

11. Pluym L, Van Nuffel A, Van Weyenberg S, Maes D (2012). The impact of lameness on (re)production results of sows. In: Proceedings of the 4th European Symposium of Porcine Health Management, 25-27 April, Bruges, Belgium, p.166.

12. Pluym LM, Van Nuffel A, Van Weyenberg S, Maes D (2013). Prevalence of lameness and claw lesions during different stages in the reproductive cycle of sows and the impact on reproduction results. Animal 7:1174-1181.

13. SAS (2002-2010). The SAS System for Windows 9.3, SAS Institute Inc., Cary, NC, USA.

14. Welfare Quality ${ }^{\circledR}$ (2009). Welfare Quality assessment protocol for pigs (sows and piglets, growing and finishing pigs). Welfare Quality $®$ Consortium. Lelystad, Netherlands. 